Feufel, M. A.

\title{
How to Uncover Sources of Unwarranted Practice Variation: A Case Study in Emergency Medicine
}

Journal article | Accepted manuscript (Postprint)

This version is available at https://doi.org/10.14279/depositonce-7078

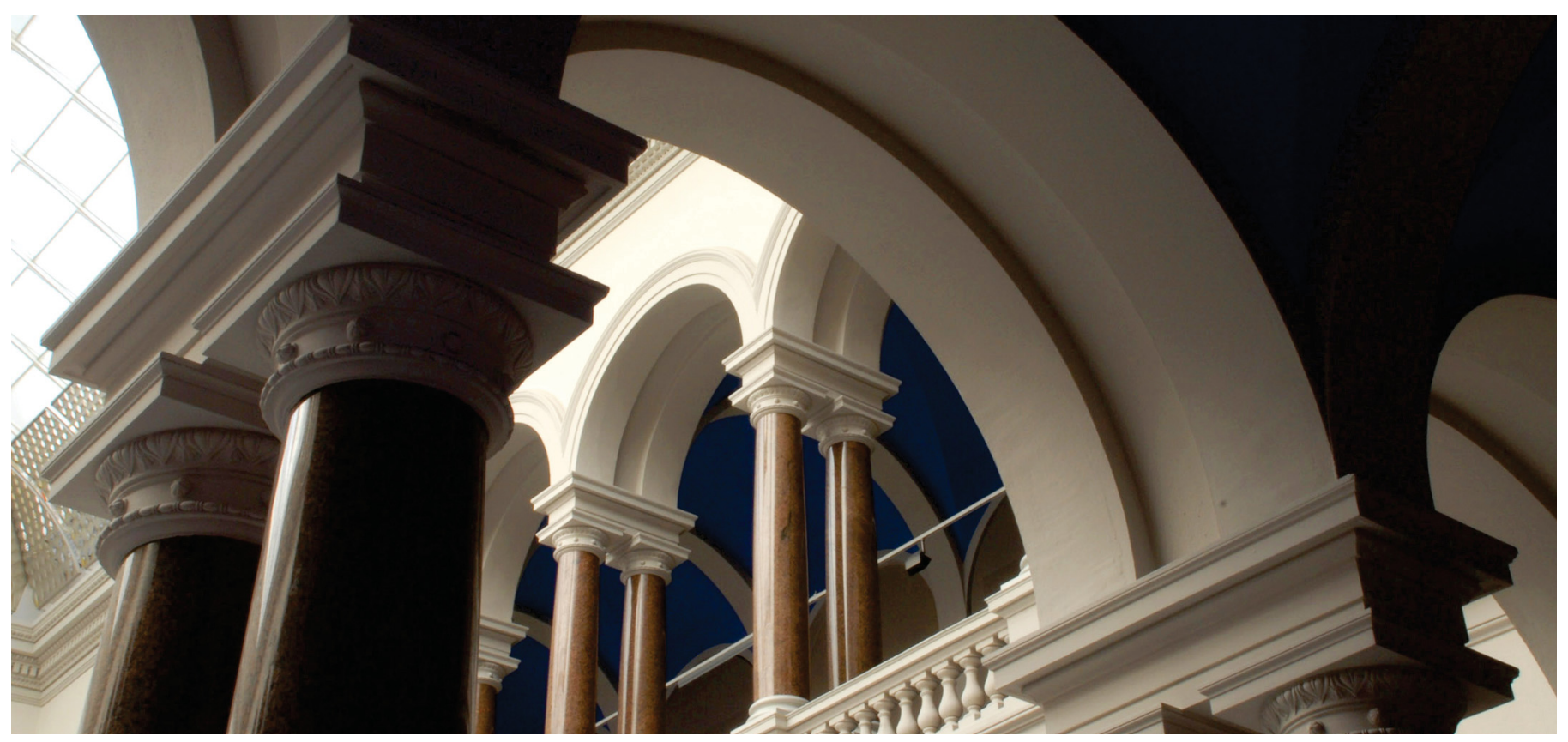

Feufel, M. A. (2018). How to Uncover Sources of Unwarranted Practice Variation: A Case Study in Emergency Medicine. Qualitative Health Research (Online First: Published May 21, 2018. pp. 1-13) https://doi.org/10.1177/1049732318774322

(c) 2018 SAGE Publications. Reprinted by permission of SAGE Publications. 


\title{
How to Uncover Sources of Unwarranted Practice Variation: A Case Study in Emergency Medicine
}

\author{
Markus A. Feufel'
}

\begin{abstract}
Forty years of statistical database analyses have demonstrated the existence of unwarranted practice variation in care delivery, that is, variations independent of medical need, evidence, or patient preference. Alas, little is known about the underlying mechanisms and thus finding interventions to reduce unwarranted variations remains difficult, hampering quality, equity, and efficiency of care. Whereas statistical analyses describe deviations from ideal patterns, ethnographically inspired analyses aim at understanding when, how, and why variations occur in practice. Based on case studies derived from shadowing emergency physicians, I demonstrate that analyzing practice variation in practice helps to (a) advance the understanding of mechanisms and (b) evaluate/expand the existing repertoire of interventions. Results revealed unmet expectations and new sources of known variations as well as interventions complementing systemic changes with those that empower individuals to better cope with the existing system. These findings highlight the benefits of mixed-methods for understanding and tackling practice variation.
\end{abstract}

\section{Keywords}

unwarranted practice variation, health policy, emergency care in the Midwest of the USA, clinical decision making, ethnography, mixed-methods

\section{Introduction}

Unwarranted practice variation is defined as the underuse, misuse, or overuse of health services independent of medical need, available evidence, or patient preferences. It has been identified as a major problem in practically all modern health care systems, raising questions concerning the quality, equity, and efficiency of care delivery practices (Brownlee et al., 2017; Glasziou et al., 2017). Despite impressive efforts at monitoring health-system performance, the authors of a recent review on the topic assert that "remedies [. . .] elude clinicians and policy makers" (Corallo et al., 2014, p. 12). Similarly, the author of an editorial on the release of the National Health Services (NHS) Atlas of Variation in Healthcare stated that "it is not clear how [an intervention] is justified from the analyses" reported in the Atlas (Mays, 2011, p. 665).

Most of the reported studies on practice variation use sophisticated statistical methods to describe patterns of performance variations based on large data repositories, such as insurance and patient registries or medical records. Their goal is to determine whether and to what extent variations in care are unwarranted because they deviate from presumed ideal levels of care for certain conditions. Such ideals are defined, for the most part, by what is considered a rational use of evidence and resources according to standards of evidence-based medicine (e.g., Sackett, Rosenberg, Gray, Haynes, \& Richardson, 1996) or what are considered the requirements and limits of an ethical use of patient preferences (e.g., Wennberg, Fisher, \& Skinner, 2002). Given the focus on performance comparison and the mostly retrospective and descriptive-correlational nature of database analyses, it is not surprising that "very few [studies] looked at the causes [. . . ] of medical practice variations" (Corallo et al., 2014, p. 5). Without an adequate understanding of the causes or mechanisms underlying both unwarranted and warranted variations, it is difficult to identify effective remedies.

To understand and target the drivers of unwarranted practice variations, authors in a recent special issue of The Lancet on practice variation suggested studying care delivery systems at the global, national, regional, and institutional levels, as well as at the level of the physician-patient encounter (Saini et al., 2017). A look at the literature suggests that a majority of studies into unwarranted practice variation focuses on the global, national, or regional level. Only a few studies explore how it "can be traced back to actions of individual patients and their health care providers" (von Stillfried, Ermakova, \& Czihal, 2017, p. 1358). Moreover, methods

'Technische Universität Berlin, Berlin, Germany

\section{Corresponding Author:}

Markus A. Feufel, Technische Universität Berlin,

Department of Psychology and Ergonomics, Division of Ergonomics,

Marchstr. 23, Sekr. MAR 3-2, 10587 Berlin, Germany.

Email: markus.feufel@tu-berlin.de 
for analyzing interactions between patients and care providers tend to be limited to quantitative approaches, including standard descriptive statistics and approaches related to graph theory and social-network analysis (Pollack, Weissman, Lemke, Hussey, \& Weiner, 2012; von Stillfried et al., 2017). Although the benefits of ethnography in health-services research have been acknowledged (e.g., Ong, 1993; Savage, 2000), to the best of my knowledge, no study has thus far used ethnographically inspired methods to explicitly understand sources of practice variation at the level of the physician-patient encounter.

My intention in this research article is to demonstrate both the methodological feasibility and the conceptual value of taking an ethnographically inspired look at the practice of practice variation and to elaborate on how this approach can complement statistical database analyses. Based on observational data derived from both shadowing and having informal conversations with emergency physicians, I will demonstrate how the structure of the health-care system, social norms and values, and clinical demand and resource supply constrain and enable variations in the interaction between physicians and patients. To highlight the benefits of a mixed-methods approach for understanding and tackling practice variation, I will specifically elaborate on how qualitative analysis can (a) advance the understanding of mechanisms underlying practice variation and (b) evaluate and expand the repertoire of interventions to increase quality, equity, and efficiency of practice variations.

\section{Method}

\section{Data Sources and Methodological Rationale}

To analyze practice variation at the level of the physician-patient encounter, I reanalyzed case studies based on ethnographically inspired observations of the everyday decision-making practices of emergency physicians. The complete data can be found in Feufel (2009) and were collected from an "emic," that is, an insider's perspective (Madden, 2017) during an immersion period of about 1.5 years and included participation in various formal and informal meetings as well as extended observation periods in emergency departments (EDs). The original goal of this study was to understand how ED physicians make decisions under time pressure and with scarce resources. Specifically, physicians were shadowed over the course of their work shifts to capture "the day-to-day dynamics of practice, especially as events emerge over time and space" (McDonald \& Simpson, 2014, p. 3).

The data were chosen because emergency medical practice is ideally suited for studying sources of variations in the coordination of care and information between health professionals and patients. Like general practitioners, ED physicians assume the role of gatekeepers, which requires interaction with and collaboration among multiple providers and specialists (Donner-Banzhoff et al., 2017). Also, ED physicians must deal with various technical, resource, and communication challenges to serve a diverse array of patients who have a potentially vast number of medical and/or social problems. Finally, unlike in community medical practices and in most hospital wards, care trajectories in the ED tend to begin and end on the same day, which facilitates observations and analyses of entire care episodes.

\section{Data Collection}

All case studies were collected in two EDs associated with two teaching hospitals of a midsize, Midwestern state university in the United States. The two EDs differed along several dimensions, ranging from size to patient population: The larger urban ED served an ethnically and socioeconomically more diverse population with everyday problems related to heart attacks, organ failures, and drug overdoses. The smaller, more rural ED served a less diverse, mainly geriatric, middle-class population with chronic complaints such as chest pain or shortness of breath.

At each ED, six physicians in training ("residents") and three fully licensed supervising physicians ("attending physicians" or "attendings") were each shadowed for an entire work shift of approximately 10 hours. The observations were balanced across day and night shifts and days of the week, totaling approximately 180 hours of observation collected over a period of about 1.5 years. Physicians were selected from a pool of about 40 attending physicians and 30 residents based on recommendations from colleagues and nursing staff. The work experience of the shadowed attending physicians ranged from 5 to 31 years, with a mean of 13 years. The resident sample consisted of two residents in each of the first, second, and third year of residency. During each shift, the observed physicians saw between 10 and 28 patients. Whereas physicians provided written consent, they informed their patients about the study and asked for verbal consent before the author (the "observer") was allowed into the room to observe. The study from which the data are reported was approved by the ethics committees of both of the involved hospitals (No. 08034) and the medical school/university (SC No. 650).

Most shadowing sessions started 5 minutes before the official start of the work shift and ended after documentation had been completed. The educational relationship between residents and supervising attending physicians naturally facilitated verbalizations of care plans and reduced the need for interruptions 
Table I. Comparison Between Statistical and Ethnographically Inspired Analyses.

\begin{tabular}{|c|c|c|}
\hline \multicolumn{2}{|c|}{ Care Pattern Statistical Database Analyses } & Ethnographically Inspired Analyses \\
\hline \multicolumn{3}{|c|}{ Effective care } \\
\hline Findings & Underuse & Used to negotiate problem ownership \\
\hline Reasons & $\begin{array}{l}\text { Lack of infrastructure to enforce } \\
\text { implementation of evidence-based "best } \\
\text { practices" for known diagnoses. }\end{array}$ & $\begin{array}{l}\text { Diagnoses were not the main goal, but allocation of problem } \\
\text { ownership. Diagnoses often remained underspecified so that } \\
\text { effective care could not immediately be provided. } \\
\text { Evidence was used to negotiate problem ownership rather than } \\
\text { to make evidence-based decisions. }\end{array}$ \\
\hline Preference-se & $\begin{array}{l}\text { Organizational structures can/must enforce } \\
\text { "best practices" for the use of evidence } \\
\text { (Wennberg, Fisher, \& Skinner, 2002). } \\
\text { nsitive care }\end{array}$ & $\begin{array}{l}\text { Organizational structures that enforce "best practices" for allocating } \\
\text { problem ownership may refocus physicians on diagnoses as a } \\
\text { prerequisite for effective care. }\end{array}$ \\
\hline Findings & Misuse & Used to increase effectiveness and efficiency of care delivery \\
\hline Reasons & $\begin{array}{l}\text { Overpowering effect of supply of resources } \\
\text { and of physicians' medical opinion. }\end{array}$ & $\begin{array}{l}\text { - Patient preferences were not only ethically desirable but also } \\
\text { essential for identifying medical need in basically all encounters. } \\
\text { - Neither physicians nor patients were prepared to } \\
\text { communicate/implement preferences and goals. }\end{array}$ \\
\hline Solutions & $\begin{array}{l}\text { - Providing better clinical evidence to } \\
\text { patients. } \\
\text { Enforcing ethical standards to include } \\
\text { patients in decision making (Fisher \& } \\
\text { Wennberg, 2003). }\end{array}$ & $\begin{array}{l}\text { - Mandatory communication and info-elicitation training for } \\
\text { health professionals, in medical education and in practice, to } \\
\text { stop the neglect of patient preferences. } \\
\text { - User-friendly instructions for patients on how to contribute to } \\
\text { care trajectories before, during, and after their episode. }\end{array}$ \\
\hline \multicolumn{3}{|c|}{ Supply-sensitive care } \\
\hline Findings & Overuse & Used to manage and trade off workload and patient safety \\
\hline Reasons & $\begin{array}{l}\text { - Lack of evidence concerning optimal } \\
\text { frequency of use of procedures. } \\
\text { - Incentive system favors full deployment } \\
\text { of available resources. }\end{array}$ & $\begin{array}{l}\text { - The stove-pipe distribution of professional responsibilities was } \\
\text { exploited to manage/distribute workload. } \\
\text { Lack of knowledge concerning available resources/expertise } \\
\text { and no feedback about rationales or impact of allocation } \\
\text { decisions. }\end{array}$ \\
\hline Solutions & $\begin{array}{l}\text { - Change of incentive system (Elshaug et } \\
\text { al., 20I7). } \\
\text { More evidence concerning optimal } \\
\text { frequency of use of procedures } \\
\text { (Wennberg, 2002; Wennberg et al., } \\
\text { 2002). }\end{array}$ & $\begin{array}{l}\text { Professional training in care logistics in addition to training in } \\
\text { biomedical knowledge and communication skills. } \\
\text { Organizational and professional structures that increase the } \\
\text { focus on the patient as a whole rather than on specialized } \\
\text { medical problems. } \\
\text { - Information systems that support providers and patients in } \\
\text { coordinating care. }\end{array}$ \\
\hline
\end{tabular}

and clarifying questions by the observer (cf. Shalin \& Bertram, 1996). If time permitted after a patient encounter or during short breaks, observation was supplemented by physicians explaining their underlying reasoning to the observer. Physicians' conversations with colleagues and patients and any explanation provided to the observer were taken down in shorthand on a notepad during in situ observations. They were transcribed after each observation to capture the semantic content of each conversation and to reflect word choices.

\section{Analytical Framework}

The analytical framework of this study is grounded in recent advances in the field of Human Factors and Ergonomics and the idea that both good and bad outcomes stem from the same source: natural variations in everyday performance (e.g., Hollnagel, 2014). Thus, to reduce bad outcomes while leveraging good ones, it is imperative to understand the sources and dynamics underlying performance variation. In the case of unwarranted practice variation, much is known about undesirable variation thanks to statistical database analyses. Much less is known about the sources of desirable variation, however. With this asymmetry in mind, the analytic framework used in this study focuses on both functional and dysfunctional aspects of performance variation in emergency medicine.

To study performance variation in emergency medicine, I relied on ethnographically inspired observations of physicians' everyday care-delivery practices. To be able to relate observations of clinical practice to statistical analyses of data registries, I based my analysis on a framework that was specifically developed for relating statistical patterns to clinical practice (Wennberg et al., 2002). Moreover, it has been recommended as a unifying "conceptual framework ... for [data] interpretation and to identify remedies" as part of a coordinated approach to advancing research on practice variation (Corallo et al., 2014, p. 12). The framework distinguishes three types of care based on "the relative 
roles of medical theory and opinion, medical evidence, the per capita supply of medical resources, and the importance and appropriateness of patients' preferences in choosing a treatment option" (Wennberg et al., 2002, p. w98f). In particular, the authors differentiate (a) effective care, which refers to interventions that every patient should receive because there is strong evidence that benefits outweigh harms; (b) preference-sensitive care, which refers to situations where patients' preferences should determine which of two or more alternative interventions is chosen; and (c) supplysensitive care, which describes situations where the supply of resources affects utilization rates, often independent of medical need and patient preference. All three types of care are firmly grounded in theoretical and/or scientific traditions. Whereas effective care is strongly related to the notion of evidence-based medicine and rational use of evidence (e.g., Sackett et al., 1996), preference-sensitive care has its roots in the concept of shared decision making (e.g., Godolphin, 2009) and patient-centered care delivery (e.g., Gigerenzer \& Gray, 2011). Supply-sensitive care is most strongly related to (health) economic theory and rational use of resources (e.g., Fisher \& Wennberg, 2003).

Based on these definitions, I parsed the observational data from the 2009 study to categorize and compare any interactions and recorded statements of physicians and patients that showed when, how, and why physicians considered (a) medical evidence, (b) patient preferences, or (c) supply of resources/expertise. The statements presented in the following "Results" section provide the most explicit examples from this collection. They are representative of the commonly observed sources of variation underlying the practice of effective, preferencesensitive, and supply-sensitive care in the ED. Deviations in the data from these commonly observed patterns will also be acknowledged.

\section{Results}

In each of the following three sections, I will first summarize findings related to patterns of effective, preference-sensitive, and supply-sensitive care identified in the literature on statistical analyses of data registries. Then I will present data from observations and informal conversations to outline related challenges during the physician-patient encounter in the ED. Finally, in each section, I will identify possible remedies for unwarranted variation based on the reported findings and contrast them with existing solutions to evaluate and broaden the existing intervention repertoire. An overview of the results is provided in Table 1 .

\section{Effective Care in Practice}

The definition of effective care suggests that services where benefits outweigh harms should be provided to all affected patients. Database analyses have demonstrated widespread underuse of effective care (Glasziou et al., 2017). One of the implicit assumptions of the research into unwarranted practice variation is that, to identify and select a treatment that can be labeled effective, a specific diagnosis has to be available. Yet this may not always be the case during emergency practice, as the following statements taken from informal conversations between two emergency physicians and the observer suggest.

Attending 1: We practice "worst case" thinking. If we cannot find a bad thing, and we don't have a diagnosis, we send [the patients] home with follow-up. Actually, if we have one, that's a bad thing. I tell my patients, "You don't want us to have an exact diagnosis, that's bad."

Attending 2: [ED care is] all about efficient prioritization. The first question is "Sick" or "not sick"?

In essence, these statements suggest that accurate diagnoses are not the main goal in the ED. As a reaction to a highly specialized health care system, ED physicians have refined their professional responsibilities from treating "anyone, anytime, anything" in the 1960s to a focus on acute and severe diseases, so-called "worst cases" (Zink, 2006). The ED physician's main task has changed from searching for specific diagnoses to making relatively unspecific categorizations of disease with direct implications for action: "Sick" patients should be prioritized because they suffer from acute and severe diseases and require immediate attention. Patients who are "not sick" from the ED physician's perspective suffer from a less critical disease and can therefore be sent "home with follow-up." In cases of ambiguity or under time pressure, not even this level of diagnostic specificity is necessary, as the following suggests:

Attending: The rule of thumb for residents is, "You can't go wrong with admitting someone. You sort it out later." That's what happened when I was working at [another] hospital. Sometimes I didn't even have time to see a patient. When I got around to checking on them, the resident had already admitted them and they were upstairs.

Although the directors of the residency program emphasized that specific diagnoses were important for improving the ensuing specificity and thus quality of (follow-up) care, as the clinician above acknowledged, during situations of high workload, "You can't go wrong with admitting someone" to the hospital. In other words, once a medical problem can be allocated as the responsibility of a fellow care provider, patients can be transferred and care delivery in the ED discontinued. Thus, a relatively unspecific but functional categorization of disease allows ED physicians to act quickly without jeopardizing patient safety.

Challenges. Despite this diagnostic leeway, not everyone can simply be admitted to the hospital or sent for follow- 
up at a nearby clinic. To send a patient to another care provider, ED physicians have to provide sufficient evidence to justify their allocation decision. The following examples demonstrate that evidence justifying the (re)allocation of responsibilities for a medical problem sometimes trumps even medical concerns.

Case 1: A resident and an attending physician discuss an 89-year-old woman with back and shoulder pain.

Attending: Maybe it's shingles.

Resident: That's my suspicion. She had it before on her leg. It may well be that shingles become visible in 24 hours.

Attending: If she has shingles already somewhere and they show up somewhere else, it would be an admit for disseminated zoster [shingles]. I made that mistake before and sent her for follow-up with the clinic; they sent her right back during the same shift. So that's something to consider.

Case 2: A resident and an attending physician talk about next steps for an uninsured patient.

Attending: This patient's troponin is up. Will you order a drug screen on this patient?

Resident: Why? You're spending taxpayers' money. What's it gonna do?

Attending: So Medicine [the admission ward] is not going "Nah, nah, nah, nah, nah" [indicating that they might not admit the patient despite good evidence].

Resident: We can give Medicine seven reasons to admit him. We can sell him as: 1 . Chest pain, cocaine induced; 2 . Hypertensive urgency; 3. Cellulitis [a bacterial infection of the skin]; 4. Renal failure; 5. Elevated troponin; 6. Hyperkalemia. Did I mention his blood pressure is 205 over 90 and his glucose is 242 ?

Attending: And Medicine is giving you seven reasons not to admit him - "His potassium was up before. But, but, but" [again indicating that it is difficult to get an uninsured patient admitted despite good medical reasons].

Both examples show that specialized providers with limited resources require sufficient evidence before accepting a patient. First, if evidence is insufficient or does not hold up to support ED physicians' allocation decisions, their colleagues do not accept the ED physician's decision and send the patient "right back." And second, in the case of an uninsured patient, additional evidence-although unnecessary from a medical perspective - needs to be gathered to support problem allocation. To understand this pattern, it is necessary to know that at the time of the above observation, the Emergency Medical Treatment \& Labor Act (EMTALA) guaranteed uninsured patients stabilizing treatment for emergency but not for chronic conditions (Centers for Medicare \& Medicaid Services,
2012). Thus, although there were "seven reasons to admit him"-symptoms and even diagnoses - the attending ED physician ordered additional tests to rule out that "his potassium was up before," which would have indicated a chronic condition, or that his condition was caused by the use of drugs. In other words, in the ED, evidence is not primarily used to identify effective care for specific diagnoses. It is rather the essential currency to justify the allocation of responsibilities for medical problems in a highly specialized health care system.

In summary, coping efforts related to a stove-pipe, that is, compartmentalized distribution of specialized expertise, as well as limited resources, have changed the ED physician's goal from diagnostic accuracy to negotiating problem ownership. Rather than searching for a specific diagnosis, they aim at (a) differentiating acute and severe diseases (their responsibility) versus "other" problems and (b) accumulating evidence to justify allocating "other" problems to specialists. Because of the narrow focus of their responsibilities, ED physicians are often led to bypass more elaborate diagnostic work, even if they know that they have not yet completely understood, let alone solved, a patient's problem.

Solutions. The vast amount of evidence documenting underuse of effective care is grounded on the idea that evidence-based standards of care should be provided for every patient with a given diagnosis (Glasziou et al., 2017). Given the present findings, an alternative explanation can be provided. In health systems with stove-pipe distributions of resources and expertise, the main challenge is not diagnostic accuracy but allocation of problem ownership, especially if patients' problems are ill-defined, ambiguous, or multifaceted. As a result, diagnoses may often be missing or underspecified (e.g., a patient is "sick" vs. "not sick") so that effective care cannot be provided until later in the care-delivery chain.

To remedy the underuse of effective care, Wennberg and colleagues have suggested that "The most important explanation...appears to be the lack of infrastructure to ensure compliance with well-accepted (evidence-based) standards of practice" (Wennberg et al., 2002, p. w99). The implied solution is that institutions can and should be committed to creating an infrastructure that enforces the correct use of the available evidence (see also Elshaug et al., 2017). Wennberg and colleagues acknowledge that examples of commitment to evidence-based practice "are not common." They suggest, however, that "Integrated health systems...can deliver effective care to almost all of their enrollees [whereas those] that contract with individual physician groups...have been less successful" (Wennberg et al., 2002, p. w105). Although the authors do not elaborate on why this might be the case, they seem to suggest that integrated systems provide and take clinical responsibility for a continuum of services. In that way, they would be better positioned to enforce organizational adherence to standard procedures than 
systems contracting with independent providers for different services are.

The findings reported here support this conclusion but provide a different explanation. Integrated systems might increase the rate of effective care because they (a) tend to reduce the incentive for (re)allocating problem ownership to an external provider and therefore (b) increase the incentive for finding a diagnosis and addressing the identified problem "inhouse." This different mechanism also suggests a different solution. Instead of enforcing a particular use of evidence, the best way to increase the use of effective care would be to standardize - through organizational structures or "best practices"- the allocation of problem ownership. By defining ideal or standard pathways for the allocation of medical problems, responsibilities for patients' problems would not have to be negotiated and efforts could readily focus on identifying and solving patients' problems.

\section{Preference-Sensitive Care in Practice}

Preference-sensitive care refers to elective services where multiple options exist, each with a particular profile of harms and benefits. Ideally, patients in need of such services should be given a choice of alternatives in line with their preferences, based on transparent information about the available evidence (informed decision making) and in cooperation with their care provider (shared decision making; for an in-depth description of this challenge see Mulley, Trimble, \& Elwyn, 2012). Database analyses of Medicare data have shown that rates of such discretionary services vary substantially across the United States (Dartmouth Atlas of Health Care, 2007).

In the ED, many situations involving choices between alternative treatments, diagnostic options, and admission or follow-up could be observed. In most cases, preference-sensitive care was provided unsystematically, depending on time and resources. As a resident acknowledged to the observer, "At some point you just become paternal and tell them, "Everything will be all right. This needs to be done.' [Explaining all risks and discussing alternatives of treatment options] takes so much time and we're always fighting that." However, when a resident had ordered pain treatment without asking the patient first, his supervisor insisted, "You are not treating the pain but the patient. Always ask if they want pain medication." In fact, this physician emphasized that "listening to the patient and not the text [book] is...key," indicating that patient input may be at least as relevant as medical theory. How can these apparently contradictory points of view concerning patient input and the role of preferences be reconciled?

To answer this question, it is worthwhile to analyze the degree of shared choice a patient has in practice, depending on whether the physician or the patient has access to relevant knowledge (e.g., about physiological principles vs. symptoms) and depending on who holds the power to implement required action (e.g., administering vs. taking medication; for a detailed analysis of these patterns, see Lippa, Feufel, Robinson, \& Shalin, 2016). I will first discuss physiciandominated situations, where physicians had both relevant knowledge and the power to act. Then I will focus on situations where physicians held the power to act but also required input from their patients to understand the problem at hand. Finally, I will describe situations where patients made preference-sensitive decisions in the absence of a physician.

Case 3: An attending physician trying to convice $a$ patient of staying in the hospital.

Attending to observer before visting the patient: Her labs are not normal. She is bleeding vaginally. Very confusing. She'll probably stay. I'm behind on her because I was ignoring her. Sometimes that happens because she is a difficult case, doesn't fit anywhere.

Attending to patient: The only thing I found is a blood test for heart disease. It's not bad but suspicious. But you may simply have menstrual cramps. I know we don't know what's going on. Do you really want to go home?

Patient: Okay then, I stay. Can I eat now?

Attending: Not as long as you have belly pain. We need to figure out what's going on.

Case 4: An attending physician to a 44-year-old woman with chest tightness.

Attending: I couldn't find anything with the tests. Your chest $\mathrm{X}$-ray looks fine, your enzymes are fine, and they should show if you had problems with your heart a couple of hours ago. But I want to keep you here overnight.

Patient: What do they want to do?

Attending: Probably a stress test [of the patient's heart].

Patient: Nah. I want to go home.

Attending: We should do at least one more blood test. You can go home after the blood test comes back negative and after I call the clinic for a follow-up appointment tomorrow.

In both examples, the physicians had the relevant biomedical knowledge and the responsibility to decide. Given that standard evaluation in the ED did not suffice to categorize the patient as "sick" or "not sick," ED physicians' professional norms suggested admitting the patient for observation to rule out a potential "worst case" related to the patients' hearts. Both patients intended to leave the ED, however, even without clear-cut information about their condition. 
Although the decision about next steps-whether to admit, whether to leave the ED, or when to eat-was under the purview of the physicians, it was only by communicating rationales and taking into account patient preference that the physicians could create a mutually acceptable trajectory of care. Thus, despite a biomedical rationale for a particular choice, physiciandominated decisions may still involve, and in some cases require, communication of clinical reasoning and coordination with patient preference.

A second type of situation was common at the beginning of most encounters, when ED physicians held the power to act but often lacked the relevant knowledge from their patients to identify the problem at hand:

\section{Case 5: A resident to an 80-year-old man with chest discomfort and shortness of breath.}

Resident: I don't think it's your heart, but we have to do some tests to be able to say for sure. It could be a cold or pneumonia. Is there anything else I need to know?

Patient's wife: His arm hurts as well. I didn't want to speak up. I know you might get upset with me when I interrupt you all the time.

Resident: No, that adds something. Now it sounds more like cardiac.

\section{Case 6: A resident and attending physician discuss a patient with fibromyalgia and a facial rash.}

Resident: She has fibromyalgia and a big red rash on her face. It looks real bad. She wants Phenergan and Dilaudid IV [a strong pain medication] and she asked me how old I was. You don't ask that if you're in pain [indicating that the patient was "not sick" from the resident's perspective but merely trying to obtain pain medication].

Attending: I know what's going on with this patient. Get basic labs for her: BMP, CBC, give her steroids and Benadryl [an antihistamine to treat allergies]. We won't reward her with a big Dilaudid dose, not for fibro. I'm sorry but I'm not a dummy.

In both cases, patients withheld firsthand information about their problems (e.g., pain in the arm) or goals (e.g., to obtain pain medication). Whereas the wife of the patient with chest discomfort thought that her input might have upset the physician, the patient with fibromyalgia may well have tried to obscure her actual motivation for coming to the ED. If patients choose to disclose their knowledge and/or motivations late or only in part, inefficiencies occur, or worse, problems are misclassified. In this sense, eliciting and understanding patient preferences, symptomatic experiences, and motivations for coming to the ED is not only ethically desirable but essential to accurately frame medical problems and avoid inefficiencies.

Finally, patients also made preference-sensitive decisions in the absence of a physician. In the literature, these patient- dominated decisions are typically associated with problems of adherence (Vermeire, Hearnshaw, Van Royen, \& Denekens, 2001). Patients make such decisions mainly about when to seek and when to discontinue care before or after the ED visit. Nonetheless, emergency physicians use the patients' preferences and the personal circumstances underlying these decisions to optimize care episodes in the ED. For instance, to guarantee treatment after the ED, a resident told her patient, "I'll call [a local pharmacy] to find out if I can find a cheap [inhaler] because you have no insurance." Similarly, an attending explained that, to avoid making a patient feel uncomfortable, "Normally I ask a social worker to talk to patients like her. But not for her. She is older and older patients think we think they are crazy when we do that." Even when deciding whether to admit or discharge a patient shortly before Christmas, an attending reasoned, "She probably doesn't [need to be admitted], she wants to. So, my workup is going to focus on finding a reason to admit her...over the holidays." Similar episodes also included pragmatic considerations of an attending physician who said, "Let's get them all admitted now [to make room for new patients] so the patients in the waiting room don't leave and come back again angry tonight" [when he was the only physician on duty]. Also, patients categorized as "not sick" were often nonetheless praised for coming in, rather than delaying their ED visit ("You did the right thing"). In other words, the patient's role as the first and final decision maker led ED physicians to accommodate patient preference in their decisions to optimize care delivery.

In summary, "listening to the patient [was] key" to providing effective and efficient care in almost all types of encounters. This finding transcends a definition of preference-sensitive care that is limited to discretionary services. Patient preference also affected care delivery when physicians had both the knowledge and the power to act, when they had the power to act but lacked sufficient knowledge to accurately frame patients' problems, and when effectiveness mainly depended on patients' decisions.

Challenges. Despite the extensive relevance of patient preference, ED physicians are not systematically trained as to when to elicit patients' preferences and when not to do so (i.e., depending on who was supervising them). More importantly, even if ED physicians try to elicit information, they sometimes lack the skills to do so effectively and reliably:

Case 7: A resident and an attending physician discuss an 89-year-old woman with back and shoulder pain.

Attending:...I would probably go ahead and do the chest workup...she is 89 , it could be a number of really bad things...

Resident (after having talked to the patient): She thinks she needs some blood again. [The patient is chronically anemic.] 
Attending: Let's just put her in. Call the [admitting physician]. Would have been nice if she had told us two hours ago. That would have made it easier. [To the observer] Do a study on patients telling us things in the first 45 minutes. I'm real nice and chatty and they still don't tell me.

Similarly, patients often seemed to have little knowledge and/or information about when and where to get care for their (medical) problem. They were often unsure as to what information to provide or when to ask which question. For some patients, the threshold for $\mathrm{ED}$ visits/communication was (too) low, congesting busy providers with minor and/or irrelevant problems. Other patients decided to see a physician (too) late or to withhold critical information, worsening prognosis. Both patient types hamper the delivery of effective and preference-sensitive care and may increase misallocation of resources.

Solutions. Fisher and Wennberg (2003) suggest two main reasons for the unsystematic use of preference-sensitive care. First, the available supply of resources, rather than patient preference, seems to be the main driver of care. Second, "treatment choices are more usually delegated to physicians" (Fisher \& Wennberg, 2003, p. 72) so that "It seems likely that individual physicians' opinions, rather than patients' preferences," explain much of the variation in the rates of preference-sensitive care (Wennberg et al., 2002, p. w101). As remedies, Fisher and Wennberg suggest improvements in clinical science. As a first solution, they suggest more and better evidence for patients concerning the benefits and risks of available options. Second, they suggest changes in ethical standards, including "systematic efforts to involve patients in important clinical decisions" (Fisher \& Wennberg, 2003, p. 76).

A look at clinical practice in EDs reveals that patient preference is indeed utilized unsystematically. But it also demonstrates that the role of preference could not be limited to the special case of discretionary services. Rather, a thorough understanding of patients' preferences is a precondition for providing effective and efficient care in practically all types of encounters. This finding coincides with the idea of shared decision making in which patients' contributions are a necessary ingredient for any good clinical decision (e.g., Godolphin, 2009; Mulley et al., 2012; Simpson et al., 1991). To fully realize this potential, better evidence and higher ethical standards must be accompanied by mandatory communication training for health professionals.

More importantly, shared decision making also requires new skills in patients. For instance, in their recipe for "Launching the Century of the Patients," Gigerenzer and Gray (2011) suggest empowering patients by helping them to better understand medical evidence (statistical literacy), their health and disease (health literacy), and how to use and navigate their health system (health-systems literacy).
A concrete method of implementation is to provide patients with easy-to-understand instructions about where best to go with what kind of complaint (e.g., family physician vs. ED) and what to ask and report during an appointment. Such instructions have been shown to help patients commit fewer errors when implementing a medical procedure (Feufel, Schneider, \& Berkel, 2010) and even motivate more patients to engage in self-care (Schneider, Feufel, \& Berkel, 2011).

\section{Supply-Sensitive Care in Practice}

The third type of practice variation is supply-sensitive care, which refers to services where "utilization rates are strongly influenced by the supply of resources," rather than medical need, evidence, or patient preference (Wennberg et al., 2002, p. w99). That is, more hospital beds tend to lead to more admissions and more CT scanners to more CT scans. During data collection in the ED, there was in fact one incident that referred to the idea of fully deploying available resources. A consultant cardiologist asked his ED colleague to "send us more patients," given that resources were not exhausted at the time. In most of the observed cases, however, ED physicians practiced supply-sensitive care to manage workload and maintain adequate levels of care:

Case 7: The resident and attending physician continue discussing the above 89-year-old woman with back and shoulder pain.

Resident to the Attending: Her creatinine is low.

Attending [after looking at the patient's previous creatinine values]: Looks like the value is within her range, she's always kind of low. How is she doing?

Resident: She looks comfortable.

Attending: I don't do anything with that. You're not gonna fix that. She's in for her back pain. I'll let somebody follow up. Just make sure somebody knows about it.

\section{Case 8: An attending physician on a 72-year-old man with abdominal pain.}

Attending to Observer: He's already been worked up for pancreatitis, but with his right-sided pain, I'm more concerned about appendicitis. It really makes no difference to me, it's the same treatment: pain and nausea meds, antibiotics, and he cannot eat anything because he might need surgery. But he's from W__. That's two and a half hours from here. I don't want him to come back in tomorrow, so I'll make sure he's fine if he's going home.

Given high workload and limited supply of resources in the ED, emergency physicians must decide which problems to focus on and when to discontinue care safely 
and efficiently. If follow-up was an option and the patient did not require immediate attention, ED physicians were able to reduce local workload by directing the patient to the responsible care provider ("You're not gonna fix that. Just make sure somebody knows about it"). Conversely, ED physicians increased efforts in the ED when it came to ruling out potentially acute and severe problems - a "worst case" - and preventing a potential lack of care later ("he's from W__. That is two and a half hours from here, so I'll make sure he's fine if he's going home"). This principle was generally followed. In particular, it was used during times of high workload and for patients with ambiguous or multiple problems (e.g., terminally ill or multimorbid patients) for which solutions could not readily be identified in the ED. Thus, the main focus of supply-sensitive care in the ED was not to exhaust available resources. It was rather a strategy that exploited the stove-pipe distribution of professional responsibilities and resources to maintain patient safety in light of a fluctuating workload.

Challenges. When providing supply-sensitive care, the major challenge for ED physicians is a lack of knowledge concerning the availability of resources and expertise as well as the costs of trading off local workload with resources tapped from the surrounding health-care system.

Case 9: An attending physician about a patient with a "Do-Not-Resuscitate-Comfort-Care" (DNR-CC) order who was transferred to the ED from a nursing home.

Attending: The patient has chronic leg pain. She got Darvocet [a pain medication] four hours ago, so she cannot get it for two hours. And [the nursing home staff] sent her here. They could have given her Vicodin or Morphine. I know they have it there. Now, [I] go into the room and say it's chronic DNR-CC, give her meds, and send her home...

Case 10: A third-year resident comes by the physicians' desk to discuss the case of a woman with an ingrown hair in the skin near her nipple.

Resident 1: She wants it taken out. It hurts her.

Resident 2: Who would you admit to? Plastic surgery?

Resident 1: Primary care?

Resident 2: Primary care sent her here. Unless she's just saying that.

Attending: General plastic surgery.

Resident 1: I don't want to do it here, it's “out of my league," I may screw up her nipple.

Resident 2: I wouldn't do it here in the ED but in a clinic with adequate follow-up, no problem.
Case 9 demonstrates that health-care providers often have no information about the rationales behind a patient transfer or feedback about the availability of resources/expertise at the establishment that the patient was transferred to. In this case, neither the ED physician seemed to have known why the nursing home had sent the patient in, nor did the nursing home seem to have a concrete idea about what ED physicians could or could not do for this patient. Case 10 describes a similar problem. It shows that high levels of specialization make it difficult - even for expert professionals - to identify who can respond to a particular medical problem and which establishment might have the resources and/or expertise to address it.

Although ED physicians practice supply-sensitive care as a locally efficient strategy for trading off workload, this strategy diffuses responsibilities among an ever-growing number of care providers and increases the necessity of coordinating care. Without adequate information about rationales for a patient transfer (e.g., lack of resources or expertise) and information about the availability of resources and expertise needed for patient transfer at another medical establishment, supplysensitive care will result in inefficiencies. More importantly, patients may be sent from one care provider to another without anyone owning, diagnosing, or addressing their problems. Thus, these logistic inadequacies not only threaten patient safety but also result in a potentially dissatisfying if not frustrating care experience for both patients and physicians.

Solutions. There are two main reasons for the overuse of supply-sensitive care as identified in the literature (Fisher \& Wennberg, 2003). A first is that the optimal frequency of scheduling revisits, running diagnostic tests, or admitting patients to the intensive care unit is currently based on individual judgments rather than guidelines because there is a lack of related scientific evidence and clinical theory. The second reason is that the current payment system in the United States favors full deployment of the available resources. It follows that changes in the incentive system (Elshaug et al., 2017) and more evidence concerning the medically appropriate frequency of use of procedures have been suggested to reduce overuse of supply-sensitive care (Wennberg, 2002; Wennberg et al., 2002).

In ED practice, supply-sensitive care is the strategy for managing workload and adequate levels of care. Thus, it is likely that supply-sensitive care cannot and should not be reduced by changing incentives and/or limiting the frequency of use of certain resources alone. Based on the presented results, at least four suggestions emerge on how existing measures may be complemented to increase effectiveness of supply-sensitive care.

First, despite the central role that resource allocation plays in managing adequate levels of care, its clinical function has not yet been acknowledged by medical decision-making theory and is rarely part of medical 
training. The presented findings suggest that clinical courses should focus on teaching care logistics on a par with biomedical considerations.

Second, most clinical information systems are thus far limited to supporting the reading and writing of medical histories, the ordering and reviewing of test results and treatments, and the implementation of patient transfers (Laerum, Ellingsen, \& Faxvaag, 2001). Logistics support is minimal and mainly focused on meeting legal and billing requirements (Jao, Helgason, \& Zych, 2009). However, information concerning local resource availability and rationales for using specific resources are necessary to help care providers manage workload more responsibly.

Third, referral from one provider to another is a coping strategy for distributing high levels of workload in a specialized health-care system. This strategy is often accompanied by a tendency to diffuse responsibilities among multiple providers. This tendency may, in part, be counteracted by an organization of care where at least one group of professionals - for instance, physician assistants or nurse practitioners - is accountable for the patient as a whole and not just one of his or her medical problems. In other words, one way to offset the increasing diffusion of responsibilities in specialized health-care systems could be to professionalize coordination of care by making it the responsibility of a particular group of professionals.

Finally, if professionals refer responsibilities for specialized medical problems to other providers, patients will ultimately also have increased responsibilities for coordinating their care experience. Thus, a final suggestion for remedying the overuse of supply-sensitive care is to help patients and their families better assume such responsibilities. One solution may be to design interfaces for electronic records management systems that help patients organize information about their disease(s), diagnoses, and therapies, including medications and possible drug interactions, as well as their appointments.

\section{Discussion}

The three categories of care that Wennberg and colleagues demarcate based on database analyses (Wennberg et al., 2002) - effective, preference-sensitive, and supply-sensitive care-are useful for analyzing the practice of practice variation at the level of the physicianpatient encounter. Also, these categories of care helped to relate the present findings to those obtained from statistical analyses of data repositories. An important result of this comparison was that the rationales assumed to underlie these categories of care could not, at least not all, be confirmed. Such a finding changes both the understanding of the problematic as well as its potential solutions. To broaden the conceptualization of patterns of practice variation, I will first summarize the main findings. Then I will elaborate on the contributions that an ethnographically inspired approach can make to understanding and tackling practice variation over what is at this point understood based solely on statistical analyses.

First, the assumed precondition for effective care-a specific diagnosis - was neither the general goal nor a reliable outcome of most encounters in the ED. Instead, ED physicians' primary task was to differentiate timecritical and severe diseases from "other" disease states (for a similar finding in intensive care units, see Shalin \& Bertram, 1996). In a second step, ED physicians accumulated evidence to justify reallocating responsibilities for "other" disease states to providers with the appropriate specialization. Thus, contrary to Wennberg and colleagues' (2002) assertion, medical evidence and theory were mainly used to justify allocation of problem ownership rather than to provide evidence-based care.

Second, in terms of preference-sensitive care, patient preferences were not only an ethical imperative in situations of discretionary care, but also essential to understanding and addressing patients' medical needs in almost all types of encounters. In most cases, medical evidence and theory could be applied only after (medical) problems had been delimited based on patients' preferences and goals. Thus, in emergency practice, physicians' understanding of patients' preferences and goals — not just a specific diagnosis — was a necessary precondition for effective and efficient care. This finding fully supports the idea of shared decision making (e.g., Godolphin, 2009; Mulley et al., 2012; Simpson et al., 1991).

Finally, the main rationale for supply-sensitive care was not to exhaust available resources but to distribute workload in a way that maintains adequate levels of care for patients. Contrary to Wennberg and colleagues' (2002) assertion, the influence of medical evidence and theory on supply-sensitive care was not weak. In a healthcare system that is marked by stove-pipe distributions of resources and expertise, they were the main justification for reallocating problems to providers.

Apart from providing new conceptual insights, the main advantage of ethnographically inspired analyses is that they help to evaluate and expand the existing repertoire of interventions. To reduce unwarranted practice variation in EDs, interventions derived from statistical database analyses tend to focus on changing systemic constraints (e.g., Wennberg et al., 2002). Examples include changes to incentive systems (e.g., favoring desirable performance outcomes rather than full deployment of resources), benchmarks (e.g., national standards for the number of physicians or hospital beds for a given population), or performance standards (e.g., adherence to the ideas of shared decision making or evidence-based medicine). Ethnographically inspired analyses provide a better understanding of how individual actors adapt their practice in light of these systemic constraints. Based on this knowledge, existing interventions can be modified and new ones developed to help rather than hinder physicians and patients in coping 
more effectively within the constraints of the existing system.

For instance, a conventional assumption is that supplysensitive care is overused because incentives favor full deployment of available resources. In the EDs observed, physicians used resource supply mainly to manage workload and maintain adequate levels of care for their patients. Thus, interventions should focus on logistics support to improve, rather than simply reduce, the use of supply-sensitive care. Similarly, shared decision making was the prerequisite for effective and efficient care in almost all care episodes observed in the ED. Thus, setting ethical standards for how to use patient preference in discretionary services can only be a partial solution. In addition, interventions should support not only health professionals but also patients with skill training and easy-to-use instructions to help them realize the potential of shared decision making across all types of care and ultimately "Launch...the Century of the Patient" (Gigerenzer \& Gray, 2011).

\section{Limitations}

Limitations relate to both the data set and the analytic framework. The data set reanalyzed for the present study was collected in 2009, well before the implementation and potential destruction of the Affordable Care Act, which has changed and will continue to change emergency practice (Nikpay, Freedman, Levy, \& Buchmueller, 2017). Of course, similar problems pertain to statistical database analyses, which are retrospective per definition. Also, the data were originally collected for a different purpose, that is, to understand how emergency physicians make decisions under time pressure and with limited resources (Feufel, 2009). Descriptive validity of the data (member checking) was evaluated by subject matter experts at the time, but this could not be replicated for the present study. Finally, shorthand allowed for swift recording of conversations in the ED setting but I may still have overheard or missed some parts of the natural conversations. Thus, although all case studies and recorded statements were selected to represent commonly observed patterns of care, some details may have been lost. Given the exclusive focus on two EDs in the United States, generalizability of concrete findings is limited, and additional ethnographic analyses of practice variation in a more diverse set of specialties and health systems (e.g., with vertical vs. horizontal integration) are needed to corroborate the present findings.

I chose the analytic framework of Wennberg and colleagues (2002) to be able to relate ethnographically inspired analyses of variations in practice patterns to the vast number of statistical analyses of unwarranted variations in databases that have been performed using this framework. Future research should also explore other frameworks (e.g., the shared decision-making paradigm) and evaluate their methodological feasibility and the conceptual value that they might add to understanding the practice of practice variation.

\section{Conclusion}

The results of this study demonstrate that ethnographically inspired analysis at the level of the physician-patient encounter complements statistical database analysis. Specifically, qualitative analyses help (a) broaden and specify the understanding of the mechanism assumed to underlie practice variation based on statistical database analysis and (b) evaluate and extend the repertoire of existing interventions. Concerning (a), the ED data suggest that the previous understanding underlying practice variation have to be broadened. Specifically, analyses of the physicianpatient encounter reveal that patients' preferences played a decisive role in the ED, not only in the delivery of discretionary services but for effective and efficient care delivery in practically all types of encounters. Also, evidence was not underused, as suggested in the literature on efficient care, nor were resources overused to fully exhaust the available supply, as suggested by research into supply-sensitive care. Both evidence and resources were used extensively to manage workload and coordinate adequate levels of care in a system marked by distributed resources and specialization. With respect to (b), interventions could be identified that would empower individual actors - physicians and patients alike - to cope more effectively and reliably with the existing system rather than having to change the entire system to reduce unwarranted and increase warranted practice variations.

The identified findings and interventions - based on observational data gathered at two EDs - highlight the benefits of a mixed-methods approach for understanding and tackling the problem of unwarranted practice variation. The intention of the present article is to inspire researchers interested in unwarranted practice variation to look for its causes as well as its remedies not only in databases but also in practice by using qualitative analytic approaches as described here. Both despite and because of their focus on the ED, the present findings need to be augmented by similar research performed within other specialties and in diverse settings. To do so, it will be necessary to bypass what is conventionally considered, according to evidence-based medicine, a rational use of evidence and resources or the limits of an ethical use of patient preference. Instead, this approach requires a fresh look at how social norms and values, as well as clinical demand and resources, enable and constrain the interaction between physicians and patients, both in practice and in the context of a particular health system.

\section{Acknowledgments}

I would like to thank Frauke Mörike, Maren Heibges, and David Messinger, as well as three anonymous reviewers, for their insightful comments on earlier versions of this article. Also, I would like to thank John Flach, Valerie Shalin, and Gerd Gigerenzer for creating the intellectual environment that made this work possible. Finally, the present analysis was only 
possible with the generous participation of the ED physicians and their patients.

\section{Declaration of Conflicting Interests}

The author declared no potential conflicts of interest with respect to the research, authorship, and/or publication of this article.

\section{Funding}

The author received no financial support for the research, authorship, and/or publication of this article.

\section{References}

Brownlee, S., Chalkidou, K., Doust, J., Elshaug, A. G., Glasziou, P., Heath, I., . . . Korenstein, D. (2017). Evidence for overuse of medical services around the world. The Lancet, 390, 156-168. doi:10.1016/S0140-6736(16)325855

Centers for Medicare \& Medicaid Services. (2012). Emergency Medical Treatment \& Labor Act (EMTALA). Retrieved from https://www.cms.gov/Regulations-andGuidance/Legislation/EMTALA/

Corallo, A. N., Croxford, R., Goodman, D. C., Bryan, E. L., Srivastava, D., \& Stukel, T. A. (2014). A systematic review of medical practice variation in OECD countries. Health Policy, 114, 5-14. doi:10.1016/j.healthpol.2013.08.002

Dartmouth Atlas of Health Care. (2007). Preference-sensitive care. Retrieved from http://www.dartmouthatlas.org/downloads/reports/preferen ce_sensitive.pdf

Donner-Banzhoff, N., Seidel, J., Sikeler, A. M., Bösner, S., Vogelmeier, M., Westram, A., . . Gigerenzer, G. (2017). The phenomenology of the diagnostic process: A primary care-based survey. Medical Decision Making, 37, 27-34. doi:10.1177/0272989X16653401

Elshaug, A. G., Rosenthal, M. B., Lavis, J. N., Brownlee, S., Schmidt, H., Nagpal, S., . . S Saini, V. (2017). Levers for addressing medical underuse and overuse: Achieving highvalue health care. The Lancet, 390, 191-202. doi:10.1016/S0140-6736(16)32586-7

Feufel, M. A. (2009). Bounded rationality in the emergency department (Doctoral dissertation, Wright State University, Dayton, $\quad \mathrm{OH})$ Retrieved from https://etd.ohiolink.edu/pg_10?0::NO:10:P10_ACCESSIO N NUM:wright1249241698

Feufel, M. A., Schneider, T. R., \& Berkel, H. J. (2010). A field test of the effects of instruction design on colorectal cancer self-screening accuracy. Health Education Research, 25, 709-723. doi:10.1093/her/cyq015

Fisher, E. S., \& Wennberg, J. E. (2003). Health care quality, geographic variations, and the challenge of supply-sensitive care. Perspectives in Biology and Medicine, 46, 69-79. doi:10.1353/pbm.2003.0004

Gigerenzer, G., \& Gray, J. A. M. (2011). Better doctors, better patients, better decisions: Envisioning health care 2020. Cambridge, MA: MIT Press.

Glasziou, P., Straus, S., Brownlee, S., Trevena, L., Dans, L., Guyatt, G., . . . Saini, V. (2017). Evidence for underuse of effective medical services around the world. The Lancet, 390, 169-177. doi:10.1016/S0140-6736(16)30946-1
Godolphin, W. (2009). Shared decision-making. Healthcare Quarterly, 12(Spec No Patient), e186-e190. doi:10.12927/hcq.2009.20947

Hollnagel, E. (2014). Safety-I and Safety-II: The Past and Future of Safety Management. Burlington, VT, USA: CRC Press.

Jao, C. S., Helgason, C. M., \& Zych, D. A. (2009). Implementing a computerized charge capture system to improve billing work flow and reduce errors in data entry. Journal of Computers, 4, 127-134.

Laerum, H., Ellingsen, G., \& Faxvaag, A. (2001). Doctors' use of electronic medical records systems in hospitals: Cross sectional survey. British Medical Journal, 323, 1344-1348. doi:10.1136/bmj.323.7325.1344

Lippa, K. D., Feufel, M. A., Robinson, F. E., \& Shalin, V. L. (2016). Navigating the decision space: Shared medical decision making as distributed cognition. Qualitative Health Research, 27, 1035-1048. doi:10.1177/1049732316665347

Madden, R. (2017). Being ethnographic: A guide to the theory and practice of ethnography. Los Angeles, London, New Delhi, Singapore, Washington DC: Sage.

Mays, N. (2011). Reducing unwarranted variations in healthcare in the English NHS. British Medical Journal, 342, Article d1849. doi:10.1136/bmj.d1849

McDonald, S., \& Simpson, B. (2014). Shadowing research in organizations: The methodological debates. Qualitative Research in Organizations and Management: An International Journal, 9, 3-20. doi:10.1108/QROM-02-2014-1204

Mulley, A. G., Trimble, C., \& Elwyn, G. (2012). Stop the silent misdiagnosis: Patients' preferences matter. British Medical Journal, 345, Article e6572. doi:10.1136/bmj.e6572

Nikpay, S., Freedman, S., Levy, H., \& Buchmueller, T. (2017). Effect of the Affordable Care Act Medicaid expansion on emergency department visits: Evidence from state-level emergency department databases. Annals of Emergency Medicine, $\quad 70(2), \quad$ 215-225.e6. doi:10.1016/j.annemergmed.2017.03.023

Ong, B. N. (1993). Ethnography in health services research. In B. N. Ong (Eds.), The practice of health services research (pp. 42-64). Boston, MA: Springer.

Pollack, C. E., Weissman, G. E., Lemke, K. W., Hussey, P. S., \& Weiner, J. P. (2012). Patient sharing among physicians and costs of care: A network analytic approach to care coordination using claims data. Journal of General Internal Medicine, 28, 459-465. doi:10.1007/s11606-012-2104-7

Sackett, D. L., Rosenberg, W. M., Gray, J. A., Haynes, R. B., \& Richardson, W. S. (1996). Evidence based medicine: What it is and what it isn't. British Medical Journal, 312, 71-72. doi: 10.1136/bmj.312.7023.71

Saini, V., Garcia-Armesto, S., Klemperer, D., Paris, V., Elshaug, A. G., Brownlee, S., . . . Fisher, E. S. (2017). Drivers of poor medical care. The Lancet, 390, 178-190. doi:10.1016/S0140-6736(16)30947-3

Savage, J. (2000). Ethnography and health care. BMJ, $321(7273)$, 1400-1402. https://doi.org/10.1136/bmj.321.7273.1400

Schneider, T. R., Feufel, M. A., \& Berkel, H. J. (2011). Promoting colorectal cancer screening in public health outreach campaigns. Human Factors, 53, 637-646. doi: $10.1177 / 0018720811427134$

Shalin, V. L., \& Bertram, D. A. (1996). Functions of expertise in a medical intensive care unit. Journal of Experimental \& 
Theoretical Artificial Intelligence, 8, 209-227. doi:10.1080/095281396147302
Simpson, M., Buckman, R., Stewart, M., Maguire, P., Lipkin, M., Novack, D., \& Till, J. (1991). Doctor-patient communication: The Toronto consensus statement. British Medical Journal, 303, 1385-1387. doi:10.1136/bmj.303.6814.1385

Stillfried, D. von, Ermakova, T., Ng, F., \& Czihal, T. (2017). Virtuelle Behandlernetzwerke. Bundesgesundheitsblatt Gesundheitsforschung - Gesundheitsschutz, 60(12), 13561371. https://doi.org/10.1007/s00103-017-2641-7

Vermeire, E., Hearnshaw, H., Van Royen, P., \& Denekens, J. (2001). Patient adherence to treatment: Three decades of research: A comprehensive review. Journal of Clinical Pharmacy and Therapeutics, 26, 331-342. doi:10.1046/j.1365-2710.2001.00363.x

Wennberg, J. E. (2002). Unwarranted variations in healthcare delivery: Implications for academic medical centres. British Medical Journal, 325, 961-964. doi:10.1136/bmj.325.7370.961

Wennberg, J. E., Fisher, E. S., \& Skinner, J. S. (2002). Geography and the debate over Medicare reform. Health Affairs (Project Hope), Suppl Web Exclusives, W96-W114

Zink, B. J. (2006). Anyone, anything, anytime: A history of emergency medicine. Philadelphia, PA: Elsevier Health Sciences.

\section{Author Biography}

Markus A. Feufel, PhD, MS, Dipl.-Ing. (FH), is an assistant professor of ergonomics. He heads the Division of Ergonomics in the Department of Psychology and Ergonomics at Technische Universität Berlin, Berlin, Germany. 